\title{
El razonamiento probatorio para el análisis de la causalidad en la responsabilidad civil: estudio de la jurisprudencia chilena*
}

\section{Lilian C. San Martín Neira* \\ 1 Jorge larroucau Torres ${ }^{* * *}$}

RESUMEN. Este artículo describe el razonamiento probatorio en los juicios de responsabilidad civil en relación con la causalidad. Sobre la base de la literatura y la regulación probatoria modernas, así como de la jurisprudencia civil chilena sobre responsabilidad médica y la que deriva de desastres naturales, el artículo demuestra que el juez cuenta con dos estrategias para desarrollar este razonamiento probatorio: primero, tener por acreditado el nexo causal mediante la prueba de la negligencia; y, segundo, cuando esta conexión funcional entre culpa y causalidad no es posible, acudir a otros criterios jurídicos, tanto generales (presunciones, sana crítica y estándares de prueba) como específicos (pérdida de oportunidad y daño probatorio).

Palabras Clave: prueba judicial, causalidad en la responsabilidad civil, presunciones, sana crítica, estándares de prueba, pérdida de oportunidad, daño probatorio.

* Fecha de recepción: 29 de octubre de 2019. Fecha de aceptación: 30 de marzo de 2020. Para citar el artículo: San Martín Neira, L. y Larroucau Torres, J., "El razonamiento probatorio para el análisis de la causalidad en la responsabilidad civil: estudio de la jurisprudencia chilena", Revista de Derecho Privado, Universidad Externado de Colombia, n. ${ }^{\circ} 40$, enero-junio 2021, 329-359, DOI: https://doi.org/10.18601/01234366.n40.12.

Este artículo forma parte del proyecto Fondecyt n.$^{\circ} 1170686$.

** Universidad Alberto Hurtado, Santiago de Chile, Chile; profesora de Derecho Civil. Doctora en Sistema Jurídico Romanista, Universidad de Roma "Tor Vergata", Roma, Italia. Licenciada en Ciencias Jurídicas y Sociales, Universidad de Concepción, Concepción, Chile. Contacto: 1sanmar@uahurtado.cl Orcid: 0000-0001-5101-2560.

*** Pontificia Universidad Católica de Valparaíso, Valparaíso, Chile; profesor de Derecho Procesal Civil. Doctor en Derecho, Universidad de Chile, Santiago de Chile, Chile. Licenciado en Ciencias Jurídicas y Sociales, Universidad de Concepción, Concepción, Chile. Contacto: jorge.larroucau@ pucv.co Orcid: 0000-0001-9893-5450. 


\title{
The Evidentiary Reasoning in Causation in Civil Liability: The Legal Criteria on which Chilean Jurisprudence is Based
}

\begin{abstract}
This article describes the evidence reasoning in civil liability judgments in relation to causation. Based on modern literature and regulation and evidentiary rules, as well as Chilean civil case law on medical responsibility and arising from natural disasters, the article demonstrates that the judges has two strategies to develop this evidentiary reasoning: first, to have for accrediting the causal link by proof of negligence; and, second, when this functional connection between negligence and causation is not possible, the judgments to turn to other legal criteria, both general (presumptions, free evaluation of evidence and standards of proof) and specifics (loss of opportunity and evidential damage principle).
\end{abstract}

KEYwords: judicial evidence, causation in civil liability, presumptions, free evaluation of evidence, standards of proof, loss of opportunity, evidential damage principle.

Sumario. Introducción. I. Distinciones relevantes para la causalidad. II. Déficit epistémico y déficit probatorio. III. Dos estrategias jurídicas a disposición del juez en el razonamiento probatorio. Conclusiones. Referencias.

\section{Introducción}

El razonamiento probatorio para establecer la causalidad en los juicios de responsabilidad civil se construye sobre múltiples distinciones. La primera de ellas apunta a la función que cumple la causalidad como fundamento y límite de la responsabilidad. Las otras distinciones relevantes son aquella que diferencia entre una dimensión material y una jurídica del nexo causal, y aquella que distingue entre causalidad genérica y causalidad específica. Un adecuado análisis de estas diversas categorías permite comprender el razonamiento judicial que funda la decisión sobre el vínculo causal.

Este artículo analiza la práctica judicial chilena relativa a la prueba de la causalidad en dos tipos de juicios: de responsabilidad civil médica y de responsabilidad civil por desastres naturales, mayoritariamente en sede extracontractual, incluida la responsabilidad extracontractual del Estado ${ }^{1}$, y en menor medida en sede contractual. La elección de este tipo de conflictos se debe a dos motivos. Por un lado, al hecho de que ambas clases de responsabilidad comparten un elemento común, en cuanto a que entre los antecedentes necesarios para la producción del daño hay uno de origen natural, la enfermedad y el desastre, respectivamente. Por otro lado,

1 En Chile, mutatis mutandi, la responsabilidad extracontractual del Estado se construye sobre las mismas bases de la responsabilidad entre particulares. VALDIVIA, J. M., Manual de derecho administrativo, Santiago, Tirant lo Blanch, 2018, 427 ss. 
a que se trata de casos con una incertidumbre causal elevada, precisamente debido a la presencia de este antecedente natural, ya que es posible que aun sin la conducta (negligente) del demandado el daño se hubiese producido igualmente.

En este contexto, este trabajo demuestra que en la práctica judicial chilena la causalidad se suele acreditar a partir de la prueba de la negligencia del demandado. Esta situación es coherente con la conexión funcional que hay entre la culpa y la causalidad, la cual, según se dirá, se remonta a los orígenes históricos de la noción de culpa y es congruente con los postulados modernos tanto del análisis económico del derecho como del derecho probatorio.

Por lo mismo, aunque la causalidad y la culpa son nociones conceptualmente diversas, el razonamiento probatorio del juez no puede escindirlas por completo cuando se trata de conflictos con una incertidumbre causal elevada. Esta es la primera estrategia con la que cuenta el juez para tener por probado el nexo causal.

Ahora bien, cuando el demandado se defiende mediante argumentos y evidencias, afirmando que el daño de la víctima se habría producido de todos modos, con independencia de que su conducta hubiese sido diligente o negligente, el juez puede acudir a una segunda estrategia para pronunciarse sobre la causalidad. En este segundo escenario, el razonamiento judicial puede apelar tanto a criterios generales -presunciones, sana crítica y estándares de prueba- como específicos del juicio de imputación civil - pérdida de la oportunidad y daño probatorio- para tener por demostrada la causalidad.

La jurisprudencia civil chilena de los últimos veinte años da cuenta del uso de estas dos estrategias.

La metodología empleada en la preparación de este trabajo contempla tres elementos: legislación, doctrina y jurisprudencia. La ley que se analiza es el ordenamiento jurídico vigente en Chile. El análisis doctrinario, en tanto, se centra específicamente en la literatura chilena y extranjera sobre prueba de la causalidad, lo que implica acotar las fuentes citadas a lo largo del trabajo y excluir las obras generales sobre responsabilidad extracontractual que no aluden al problema de la causalidad en particular. El uso de la doctrina extranjera, en tanto, tiene por objetivo ilustrar las discusiones actuales sobre las dos estrategias que se exponen en este artículo, sin pretender ser un estudio de derecho comparado. Para el análisis jurisprudencial, finalmente, se consideraron las sentencias de la Corte Suprema chilena, sin perjuicio de tener en cuenta asimismo las decisiones de las instancias judiciales, sobre todo en lo relativo al establecimiento de los hechos. La selección de los fallos se hizo a través de motores de búsqueda de jurisprudencia disponibles en $\mathrm{Chile}^{2}$, los cuales se confrontaron luego con la información disponible en la página web del Poder Judicial chileno, que para todos los efectos constituye la fuente oficial de tales fallos ${ }^{3}$. 


\section{Distinciones relevantes para la causalidad}

\section{A. Las funciones de la causalidad: fundamento y límite de la responsabilidad}

La causalidad, en cuanto elemento de la responsabilidad civil, cumple dos funciones, pues se erige en fundamento y límite de la misma ${ }^{4}$. Es un fundamento porque, para que tenga lugar la responsabilidad, el hecho del agente y el daño invocado por la víctima deben vincularse entre sí, el agente debe ser el 'causante' del daño (an debeatur). Y es un límite ya que el daño indemnizable es únicamente aquel que pueda conectarse con la actividad del agente (quantum respondeatur). En este último punto la causalidad es la contrapartida del principio de reparación integral del daño.

Esta primera distinción es relevante para la prueba judicial de este requisito del juicio de imputación, pues, como se verá, es posible y justificable establecer reglas procesales y probatorias diferenciadas para cada una de estas funciones de la causalidad.

Estas dos funciones del nexo causal dan lugar a dos puntos de prueba diversos en la resolución judicial que recibe la causa a prueba (art. 318 c.p.c. de 1903): un primer punto sustancial controvertido relativo a la autoría y un segundo punto sustancial controvertido referido al monto. En ambos puntos de prueba se mezclan elementos materiales y jurídicos de la causalidad, de modo que el razonamiento judicial empleado para decidirlos comparte un mismo esquema hermenéutico ${ }^{5}$.

\section{B. Causalidad material y causalidad jurídica}

La segunda distinción relevante para la prueba judicial de la causalidad es la que distingue entre la causalidad material y la causalidad jurídica. Este binomio depende de si el juicio realizado para llegar a su establecimiento se limita a un análisis estrictamente fáctico o bien comporta un razonamiento jurídico de selección de los factores materialmente necesarios para producir el daño. Estas dos dimensiones de la causalidad son indispensables para el juicio de imputación civil ${ }^{6}$.

La causalidad material (o natural) viene dada por la posibilidad de conectar en el plano fáctico el daño sufrido por la víctima con el hecho del agente. Para llegar a

4 Barros Bourie, E., Tratado de responsabilidad civil extracontractual, Santiago, Jurídica de Chile, 2006, 226 ss.; Castronovo, C., Responsabilità civile, Milano, Giuffrè, 2018, 349 ss., este último habla de causalità del fatto e causalità del danno.

5 Larroucau Torres, J., "Razonamiento hermenéutico y 'hechos sustanciales controvertidos"”, Revista Chilena de Derecho, vol. 44, n. ${ }^{\circ} 1,2017,166-169$.

6 Para las referencias de la doctrina chilena sobre este tema, véase VARGAS PINTO, T. (ed.), "La relación de causalidad. Análisis de su relevancia en la responsabilidad civil y penal", Cuadernos de Extensión Jurídica, 15, Santiago, Universidad de los Andes, 2008, passim; Krause MuÑoz, M. S., "La relación de causalidad, ¿ 'Quaestio facti o quaestio iuris'?”, Revista de Derecho, Universidad Austral de Chile, 2014, 82 ss. 
esta conexión se ha recurrido al llamado test de la conditio sine qua non. Como es sabido, este test comporta un método de identificación de las condiciones fácticas que han concurrido a la producción del daño a través de un ejercicio hipotético: si, suprimida mentalmente una determinada condición, el daño desaparece, se concluye que ella guarda una relación de causalidad material con ese daño y es candidata a ser considerada jurídicamente "la causa" del mismo; por el contrario, si el daño se mantiene incluso cuando tal hecho desaparece, se concluye que dicha condición es del todo irrelevante a efectos causales.

De este modo, el test de la conditio sine qua non permite identificar todas las condiciones que han concurrido a la producción del daño; sin embargo, como resultado de este test no puede llegar a establecerse la condición (o las condiciones) jurídicamente determinante para la producción del daño, ya que todas las condiciones -incluida la conducta de la propia víctima- se alinean en un mismo plano de relevancia: cualquiera de las condiciones relevantes que se elimine, por insignificante que ella parezca, hace desaparecer el daño; de allí que se le llame también test de la "equivalencia de las condiciones".

Esta amplitud ha llevado a identificar criterios de atribución causal que permitan acotar el rango entre todas las condiciones pre-identificadas como relevantes a efectos de la producción del daño. Estos criterios permiten diferenciar aquellas condiciones que jurídicamente podrán considerarse "causas" del mismo de aquellas otras condiciones que son jurídicamente irrelevantes. En este caso la dogmática civil habla de la "causalidad jurídica" o, siguiendo a la dogmática penal, de la "imputación objetiva" del daño.

La causalidad jurídica, por tanto, le permite al juez decidir que una (o más) condición material del daño es relevante a efectos de atribuirle a su autor el carácter de "causante" del daño.

\section{Causalidad genérica y causalidad específica}

Una tercera distinción relevante a estos efectos es aquella que distingue entre causalidad en sentido genérico y causalidad en sentido específico ${ }^{7}$.

La causalidad genérica describe la aptitud de la conducta del demandado para producir el tipo de daño que sufrió la víctima. La causalidad genérica es usualmente asumida, sin necesidad de prueba alguna, y en los casos en que ella presenta dificultades puede probarse sobre la base de probabilidades estadísticas y generalizaciones

7 Para esta distinción en Chile, véase Accattino Scagliotti, D. "Incertidumbre, probabilidad y prueba de la causalidad en el derecho de daños. Análisis de la doctrina del incremento del riesgo a más del doble”, en Marín, J. y Schopf Olea, A. (eds.), Lo público y lo privado en el Derecho. Estudios en homenaje al profesor Enrique Barros Bourie, Santiago, Thomson Reuters, 2017, 697 ss.; BANFI DEL Río, C. "La causalidad en casos de responsabilidad civil por mesotelioma: una mirada al derecho chileno e inglés", en Marín, J. y Schopf Olea, A. (eds.), Lo público y lo privado en el derecho. Estudios en homenaje al profesor Enrique Barros Bourie, Santiago, Thomson Reuters, 2017, 738 y 752. 
o máximas de la experiencia ${ }^{8}$. La causalidad específica, en cambio, exige demostrar que efectivamente el daño concreto que sufrió la víctima se produjo por la conducta del demandado, lo que implica superar el test de la conditio sine qua non, sin perjuicio de que, como se dirá en lo sucesivo, la doctrina ha intentado superar la necesidad de este test a través de criterios jurídicos que terminan por acercar la causalidad material a la causalidad jurídica.

\section{Déficit epistémico y déficit probatorio}

La prueba del nexo causal en un proceso judicial se basa en las tres distinciones recién expuestas. En el marco de la causalidad como fundamento, la prueba de la causalidad natural se construye a partir de la equivalencia de las condiciones. Tal como se dijo, este enfoque sostiene que si al suprimirse la conducta (acción u omisión) del demandado el daño desaparece, entonces no hay un nexo causal entre ambos hechos. Este razonamiento es muy simple, pero no siempre es sencillo de llevar a cabo, pues supone la acreditación de un contrafáctico, esto es, reemplazar la situación efectivamente acontecida por una que no tuvo o no podrá tener lugar ${ }^{9}$. Como explica Honoré, citando a John Leslie Mackie, reflexiones de ese tipo "involucran afirmaciones acerca de qué habría pasado en el mundo si se hubiera realizado algo distinto" 10 , pero frecuentemente no se dispone de antecedentes suficientes para suponer qué es ese algo distinto, ni tampoco para suponer que ello habría llevado a un proceso causal diferente ${ }^{11}$.

La incertidumbre causal que caracteriza a los juicios de responsabilidad civil deriva de esa circunstancia. Esto implica que los litigantes enfrenten no solo un déficit probatorio - es decir, que no siempre cuenten con medios de prueba suficiente para acreditar sus aseveraciones-, sino también un déficit epistémico -esto es, que bajo ningún respecto es posible eliminar razonablemente la incertidumbre asociada al caso-. Para ilustrar este doble desafío -el déficit epistémico y el déficit probatorioen la reciente jurisprudencia chilena, es útil acudir a dos tipos de juicios en donde los mismos se expresan con claridad: la responsabilidad civil médica y la responsabilidad civil asociada a desastres naturales.

8 Puppe, I. y Wright, R. W., "Causation in the law: philosophy, doctrine and practice", en Infantino M. y Zervogianni, E. (eds.), Causation in European Tort Law, Cambridge, Cambridge University Press, 2017, 54.

9 Sobre los contrafácticos en relación con los juicios causales, véanse RATTI, G. B., "Los contrafácticos en el derecho. Un inventario de problemas", en Papayannis, D. M. (ed.), Causalidad y atribución de responsabilidad, Madrid, Marcial Pons, 2014, 95 ss.; Menzies, P., "Counterfactual theories of causation", en Stanford Encyclopedia of Philosophy, disponible en: https://plato.stanford.edu/ entries/causation-counterfactual/ [consultado el 25 marzo de 2020]; PuPPE, I. y WRIGHT, R. W. "Causation in the Law", cit., 29 ss.

10 Honoré, T., "Condiciones necesarias y suficientes en la responsabilidad extracontractual", A. Pino y A. Ibáñez (trads.), Revista Chilena de Derecho, vol. 40, n. 3, 2013, 1082.

11 Ibíd., 1082. 
Estos casos muestran que el test de la conditio sine qua non pierde utilidad en la litigación civil. A raíz de la presencia de la condición natural, son muy pocos los juicios en que se puede establecer que efectivamente el daño no se hubiera producido de no haber mediado la conducta del demandado, por lo que, en principio, el juez debería tener por no probado el nexo causal y rechazar la demanda.

Esto fue precisamente lo que ocurrió en los juicios de responsabilidad médica en un primer momento, a fines de la década de 1990 y comienzos de este siglo en Chile. Esta fue la respuesta judicial en situaciones que son más o menos simples, como una atención de urgencia por heridas cortopunzantes proferidas por un tercero en que el paciente muere a causa de tal agresión y no por haber sido atendido en forma tardía, casos en que los jueces rechazaron las demandas civiles ${ }^{12}$. Lo mismo ocurrió en otros casos más complejos en donde la incertidumbre causal era mucho más elevada ${ }^{13}$, por ejemplo, cuando los jueces exigieron una prueba específica de la causalidad material en casos como el de un hijo que murió por un traumatismo craneoencefálico tras emplearse fórceps durante la cesárea ${ }^{14}$, o en el de trece niños y niñas en tratamiento oncológico en un lugar que no tenía autorización sanitaria y que fueron contagiados con el virus de la hepatitis $\mathrm{B}^{15}$. Para rechazar las demandas, los jueces emplearon diferentes fórmulas, como el que no se había demostrado que el daño había derivado "única y exclusivamente por un mal funcionamiento del Servicio" 16 , o bien, que "no se determinó en forma indubitada cuál fue [su] causa precisa" $"$. En otras palabras, a raíz del fracaso del test de la conditio sine qua non, los jueces decidieron que no se trató de casos de responsabilidad, sino de infortunio.

\section{Dos estrategias jurídicas a disposición del juez en el razonamiento probatorio}

Para evitar que todos los juicios de responsabilidad con incertidumbre causal elevada terminen con el rechazo de la demanda es necesario reconocer que la prueba judicial de la causalidad no se agota en una cuestión exclusivamente material -tributaria de las leyes de la naturaleza-, sino que el juez tiene la posibilidad de reconstruir la cadena de condiciones que dan lugar al daño a través de criterios jurídicos. Esto es posible y justificado por el hecho de que, a diferencia de lo que ocurre con la causalidad en materia científica, e incluso filosófica, en los juicios de responsabilidad civil el juez

12 Corte Suprema, 26 de junio de 2008, rol. n. ${ }^{\circ}$ 5667-2006. Corte de Apelaciones de Punta Arenas, 29 de mayo de 2009, rol. n. $23-2007$.

13 Larroucau Torres, J., “Cómo se prueba la responsabilidad civil médica en la justicia chilena?”, Revista de Derecho de la Universidad Austral, vol. 27, n. ${ }^{\circ} 2,2014,56-58$.

14 Corte de Apelaciones de Santiago, 31 de julio de 1991, Gaceta Jurídica, n. ${ }^{\circ} 133$.

15 Corte Suprema, 19 de enero de 2012, rol. n. ${ }^{\circ}$ 7086-2009.

16 Corte Suprema, 14 de octubre de 2008, rol. n. ${ }^{\circ}$ 1976-2007.

17 Corte Suprema, 28 de marzo de 2007, rol n. ${ }^{\circ} 3611-2006$. 
no busca establecer la verdad absoluta en términos de sortear el déficit epistémico, sino que, por tratarse de un juicio de imputación, le basta con establecer que existen razones jurídicas suficientes para atribuir la ocurrencia del daño al demandado.

Cobra así relevancia la distinción entre causalidad genérica y específica antes formulada. Al efecto se sostiene que el test de la conditio sine qua non debe necesariamente operar en sede de causalidad específica, pero no a nivel de causalidad genérica, la cual se puede demostrar mediante máximas de la experiencia o incluso con prueba estadística. En concreto, el demandante debe acreditar que la conducta del demandado es apta para producir el tipo de daño que invoca (causalidad genérica) y, además, que tal conducta efectivamente fue la que produjo el daño de la víctima.

Tal entendimiento, sin embargo, no resuelve los problemas probatorios que supone la acreditación de la causalidad específica, pues el demandante sigue sujeto al test de la conditio sine qua non. Para sortear estos problemas, la dogmática civil ha elaborado criterios que en buena medida han producido un acercamiento entre la llamada causalidad natural y la causalidad jurídica, pues se trata de criterios que lidian con la incerteza causal en el plano normativo. Esta situación es reconocida por la doctrina, al punto que se ha llegado a hablar de "la juridización" de la causalidad material, aludiendo al hecho de que ya no se busca la comprobación del nexo causal en un sentido natural (o científico) sino que dicho nexo se establece mediante criterios jurídicos, que permiten una repartición de los riesgos de una determinada actividad entre las partes involucradas ${ }^{18}$.

La doctrina chilena no ha hecho hincapié en el proceso de juridización de la causalidad material, pero también ha intentado resolver problemas de incertidumbre causal a través de criterios que son más bien jurídicos, tomados de la experiencia comparada y de reglas procesales vigentes en el ordenamiento jurídico.

El análisis de esos criterios se aborda en la última parte de este trabajo. Por ahora es preciso señalar que la incertidumbre causal suele resolverse mediante una estrategia concreta: la conexión funcional entre culpa y causalidad, en donde la prueba de la causalidad descansa en la prueba de la culpa. El siguiente apartado presenta las diversas razones históricas y dogmáticas que justifican esta práctica judicial.

\section{A. Conexión funcional entre culpa y causalidad}

La responsabilidad civil se edifica con base en elementos relacionados entre sí. En este sentido, desde un punto de vista conceptual y normativo, el juicio de imputación

18 NocCo, L., "Causalità: dalla probabilità lógica (nuovamente) alla probabilità statistica, la Cassazione civile fa retromarcia", Danno e responsabilità, n. ${ }^{\circ} 12,2006,1243$; Múrtula Lafuente, V., "Causalidad alternativa e indeterminación del causante del daño en la responsabilidad civil", [en línea], InDret, 2, 2006, 18-19, disponible en: http://www.indret.com/pdf/351_es.pdf [consultado el 31 de enero de 2019]; MoréteAu, O., "Causal uncertainty and proportional liability in France”, en GILEAD, I., Green, M. y Косн, B. (eds.), Proportional Liability: Analitical and Comparative Perspectives, Berlin-Boston, De Gruyter, 2013, 141. 
civil contempla como requisitos la culpa y la causalidad, entre los cuales hay una conexión funcional. Esta conexión se arraiga en el origen mismo de la culpa como categoría jurídica, cuyo rol como elemento normativo fue dirimir problemas de causalidad material en la aplicación de la lex Aquilia ${ }^{19}$.

En efecto, según ha demostrado Sandro Schipani ${ }^{20}$, los juristas romanos desarrollaron la noción de culpa precisamente para identificar al 'causante' del daño cuando en su producción habían intervenido al mismo tiempo dos o más conductas. Por lo mismo, desde un punto de vista histórico, la culpa constituye el primer criterio jurídico de determinación de la causalidad en la tradición occidental ${ }^{21}$.

Sin perjuicio de que la evolución del pensamiento jurídico ha llevado a independizar la culpa de la causalidad, lo cierto es que todavía es posible observar una estrecha relación entre ellas, a tal punto que es posible afirmar que, en un sistema de responsabilidad civil basado en la culpa, frente a dos condiciones necesarias del daño, una 'inocente' y otra 'culpable', el derecho tiende a considerar 'causante' del daño a quien ha aportado la condición culpable. Así lo han observado juristas de diversas tradiciones, tales como Honoré ${ }^{22}$, Cane $^{23}$ y Reglero Campos ${ }^{24}$. En Chile, en tanto, una parte de la dogmática civil contemporánea también ha reconocido esta conexión funcional entre ambos elementos, por ejemplo, a propósito de la noción de culpa en el derecho romano, o bien de la función del dolo en la responsabilidad extracontractual ${ }^{25}$.

Esto no significa que la culpa sea el único criterio de atribución causal en la práctica judicial, ya que en muchas ocasiones el riesgo generado con la actividad

19 Mayores antecedentes en SAN MARTín NeIRA, L., La culpa de la víctima en la responsabilidad civil, Santiago, DER, 2018, 50 ss.

20 Por todos, Schipani, S., Contributi romanistici al sistema della responsabilità extracontrattuale, Torino, Giappichelli, 2009, passim; SchIPANI, S., "Fronteras actuales del hecho ilícito y relecturas de los digestos", en Alferillo, P. et al., Liber Amicorum en homenaje al prof. Dr. Luis Moisset de Espanés, t. I, Córdoba, Advocatus, 173-192. Un resumen de esta doctrina en LARrouCau Torres, J., Culpa y dolo en la responsabilidad extracontractual, Santiago, LexisNexis, 2007, 38 ss.

21 Esta idea fue especialmente resaltada por Rudolf von Jhering, quien expresamente afirma que la refinación del pensamiento jurídico romano llevó a desechar las apariencias y a reemplazarlas por el juicio de la ciencia: "para la cuestión de la indemnización de perjuicios esto consistió en imponer ante el criterio de la causalidad externa del hecho, el de la causalidad interna de la inculpación". Von JHERING, R., El elemento de la culpabilidad en el derecho privado romano, J. L. Guzmán Dalbora (trad.), Buenos Aires, Euro, 2013, 106.

22 Honoré, T., "Condiciones necesarias y suficientes”, cit., 1081.

23 CANE, P., "Responsibility and fault: a relational and functional approach to responsibility", CANE, P. y GARDNER, J. (coords.), Relating to Responsibility. Essays for Tony Honoré on his Eightieth Birthday, Oxford-Oregon, Hart, 2001, 89 y 107.

24 Reglero Campos, F. y Bustos Lagos, J. (coords.), Tratado de responsabilidad civil, t. I, 5. a ed., Cizur Menor, Thomson Reuters-Aranzadi, 2014, 776.

25 Aedo Barrena, C., "La cuestión causal en la 'lex Aquilia' y su solución mediante el mecanismo de la culpa”, Revista de Estudios Histórico-Jurídicos, Valparaíso, n. ${ }^{\circ}$ XXXVII, 2015, 37-75; BANFI DEL Río, C., "Relevancia del dolo en la responsabilidad extracontractual chilena: una relectura desde el derecho inglés", Revista de Derecho Universidad Católica del Norte, 2017, n. 2, 96 ss. 
del agente culpable no se relaciona directamente con el daño producido. Tal como se anticipó, para estos casos el juez dispone de otros criterios jurídicos, conocidos como "teorías de la causalidad" o de "imputación objetiva", que le permiten descartar el nexo causal prima facie establecido mediante la culpa entre la conducta del demandado y el perjuicio de la víctima ${ }^{26}$.

Para refrendar esta conexión funcional entre culpa y causalidad es útil considerar lo que se ha sostenido por autores pertenecientes a la corriente del análisis económico del derecho. Como explica Papayannis, las diversas vertientes del análisis económico del derecho convergen en sostener que debe considerarse responsable del daño a quien estaba en mejor posición de evitarlo, pues se asume que este sujeto tiene un deber en tal sentido. De lo cual se sigue que, "si el agente fue culpable, en cuanto pudo haber evitado el daño y no lo hizo, entonces, es causante en sentido económico. Ningún juicio de causalidad es independiente de un juicio de culpa, y ningún juicio de culpabilidad es independiente de un juicio de causalidad ${ }^{27}$. Cabe señalar que, en opinión de este mismo autor, esta secuencia lógica evidenciaría un déficit en la estructura argumental de tales autores, pues -afirma- "los juristas entienden que la verdad de una afirmación causal no incide en forma alguna sobre la evaluación de la culpa, y viceversa" ${ }^{28}$. Esta última frase pasa por alto lo ya dicho en cuanto a que en el pensamiento jurídico occidental el juicio de causalidad no es completamente independiente del juicio de culpa, de manera que no es una mera coincidencia que, por diversos caminos, los autores modernos lleguen a la misma conclusión.

Todo lo anterior explica la relevancia probatoria que tiene la prueba de la culpa en la prueba de la causalidad. Esto es particularmente evidente cuando se trata de daños en el contexto de la responsabilidad médica, o bien de la que deriva de los desastres naturales. En estos dos escenarios se produce la concurrencia material entre una condición natural (enfermedad o fenómeno natural), que será siempre 'inocente', y una actividad humana, que será considerada 'causa' del daño en la medida en que sea culpable. Si no se prueba esta negligencia, la 'causa' del daño quedará radicada en la condición natural.

De allí que en la jurisprudencia chilena se afirme o se descarte la relación de causalidad entre la actuación médica y el daño sobre la base de si está o no acreditada la mala praxis médica ${ }^{29}$; y, en el caso de los fenómenos naturales con poder destructivo, se afirme que estos han constituido un caso fortuito $-\mathrm{y}$, por ende, que

26 Para más antecedentes, véase SAN Martín NeIRA, L., La culpa de la víctima, cit., 54 ss.

27 Cfr. Papayannis, D., El derecho privado como cuestión pública, Bogotá, Universidad Externado de Colombia, 2016, 91 .

28 Ibíd., 92. En un sentido similar, PAPAYANnIs, D., Causalidad y atribución de responsabilidad, Madrid, Marcial Pons, 2014, 93 ss.

29 V. gr., Corte Suprema, 19 de junio de 2014, rol n. ${ }^{\circ}$ 5817-2013; Corte Suprema, 20 de diciembre de 2016, rol n. ${ }^{\circ} 73778-2016$; Corte Suprema, 29 de enero de 2018, rol n. ${ }^{\circ}$ 19182-2017; Corte Suprema, 8 de marzo de 2018, rol n. ${ }^{\circ} 35764-2017$; Corte Suprema, 25 de julio de 2018, rol n. ${ }^{\circ} 30264-2017$; 
han sido 'la causa' del daño- cuando no está probada la culpa del demandado y viceversa ${ }^{30}$.

Lo dicho hasta aquí se aprecia palmariamente en los juicios relativos a daños en los edificios con ocasión del terremoto y el posterior tsunami ocurridos el día 27 de febrero del año 2010 en Chile (en adelante, el 27F). En esta serie de juicios es indiscutido que el terremoto es una conditio sine qua non del daño, de modo que la pregunta que se plantearon los tribunales fue si los edificios se dañaron porque 'estaban mal construidos' o bien 'a raíz del terremoto' ${ }^{31}$. Cada vez que se tuvo por probada una infracción a la lex artis en la construcción, el demandado fue considerado 'causante' del daño; en los demás casos se estableció que hubo caso fortuito ${ }^{32}$. A modo de ejemplo, cabe citar la sentencia dictada en el juicio seguido a propósito de la inclinación sufrida por un grupo de viviendas en la Región del Biobío, donde, confirmando las decisiones de instancia, la Corte Suprema sostuvo:

En lo sustancial, los jueces dejan asentado, en el basamento cuadragésimo segundo, que "la realización de los rellenos se hizo conforme a la lex artis y a las especificaciones técnicas elaborados por empresas certificadas", para colegir, en el fundamento siguiente, que la prueba rendida no permite concluir "que la inclinación o asentamiento de las viviendas corresponde a daños o defectos en la construcción, sean éstos la mala compactación o deficiencias de los rellenos u otra causa distinta a los efectos propios de un sismo, más aún cuando en la casi totalidad de los casos, las Compañías de Seguros indemnizaron los daños en la construcción de las viviendas, de acuerdo a los montos asegurados, considerando como causa de los mismos, el sismo y su magnitud, en lugar de atribuirlo a algún defecto en la construcción"33.

Corte Suprema, 3 de septiembre de 2018, rol n. ${ }^{\circ}$ 826-2018; Corte Suprema, 3 de septiembre de 2018, rol n. ${ }^{\circ}$ 40328-2017; Corte Suprema, 27 de septiembre de 2018, rol n. ${ }^{\circ}$ 14895-2018.

30 V. gr., Corte Suprema, 27 de noviembre de 2003, rol n. ${ }^{\circ} 4680-2002$; Corte Suprema, 26 de mayo de 2005, rol n. ${ }^{\circ}$ 41-2004; Corte Suprema, 15 de octubre de 2008, rol n. ${ }^{\circ} 3151-2007$; Corte Suprema, 4 de noviembre de 2008, rol n. ${ }^{\circ} 3003-2008$; Corte Suprema, 18 de octubre de 2010, rol n. ${ }^{\circ} 3060-2010$; Corte Suprema, 18 de octubre de 2012, rol n. ${ }^{\circ} 8847-2009$; Corte Suprema, 6 de marzo de 2013, rol n. ${ }^{\circ}$ 9074-2011; Corte Suprema, 11 de abril de 2013, rol n. ${ }^{\circ} 3864-2011$; Corte Suprema, 7 de mayo de 2014, rol n. ${ }^{\circ} 4553-2013$; Corte Suprema, 7 de mayo de 2014, rol n. ${ }^{\circ} 7610-2012$; Corte Suprema, 17 de mayo de 2017, rol n. ${ }^{\circ} 22185-2016$; Corte Suprema, 21 de agosto de 2017, rol n. ${ }^{\circ} 10373-2017$; Corte Suprema, 17 de julio de 2019, rol n. ${ }^{\circ} 40703-2017$.

31 V. gr., Corte Suprema, 4 de enero de 2016, rol n. ${ }^{\circ} 4886-2015$; Corte Suprema, 10 de marzo de 2016, rol n. 33651-2015; Corte Suprema, 14 de junio de 2016, rol v16952-2016; Corte Suprema, 30 de diciembre de 2016, rol n. ${ }^{\circ}$ 19724-2015; Corte Suprema, 13 de noviembre de 2017, rol n. ${ }^{\circ}$ 6860-2017; Corte Suprema, 25 de enero de 2017, rol n. ${ }^{\circ} 24349-2016$; Corte Suprema, 17 de julio de 2019, rol n. ${ }^{\circ}$ 40703-2017; Corte Suprema, 23 de julio de 2019, rol n. ${ }^{\circ}$ 1248-2018.

32 V. gr., Corte Suprema, 30 de diciembre de 2016, rol n. ${ }^{\circ}$ 19724-2015; Corte Suprema, 10 de marzo de 2016, rol n. ${ }^{\circ} 33651-2015$; Corte Suprema, 25 de enero de 2017, rol n. ${ }^{\circ}$ 24349-2016; Corte Suprema, 4 de enero de 2016, rol n. ${ }^{\circ} 4886-2015$.

33 Cfr. Corte Suprema, 23 de julio de 2019, rol n. ${ }^{\circ}$ 1248-2018. 
En síntesis, la incertidumbre causal es resuelta por los jueces mediante esta conexión funcional entre culpa y causalidad. Luego, esta estrategia se ve desafiada cuando el demandado se defiende sobre la base de que el daño se habría producido igualmente sin su conducta negligente.

En este segundo escenario, los déficits probatorio y epistémico pueden ser superados mediante otros criterios jurídicos distintos a la negligencia. Al análisis del modo en que operan estos criterios en el razonamiento judicial se dedica el resto del trabajo.

\section{B. Criterios jurídicos para resolver problemas de incertidumbre causal}

La prueba judicial en casos con incertidumbre causal elevada que no puede resolverse mediante la prueba de la culpa ha dado lugar al empleo de otros criterios jurídicos, algunos de los cuales son generales -en tanto se aplican a la prueba judicial de cualquier hecho sustancial controvertido-, como las presunciones, la sana crítica y los estándares probatorios, y otros específicos -elaborados puntualmente para lidiar con los problemas de incertidumbre causal en la responsabilidad civil-, como la pérdida de la oportunidad y el daño probatorio.

A continuación analizamos el modo en que cada uno de ellos ha sido recogido por la jurisprudencia civil chilena para resolver principalmente el déficit probatorio y también, en algunos casos, el déficit epistémico con respecto al nexo causal.

\section{Criterios generales}

\section{a. Presunciones y sana crítica}

El régimen general de valoración de prueba en la litigación civil chilena puede ser calificado de mixto, pues en él coexisten varias reglas tasadas (sobre todo en relación con el valor probatorio de los documentos y de los testigos) con algunas disposiciones de libertad de prueba ${ }^{34}$. La más importante entre estas últimas es la regla que ordena al juez valorar el peritaje de acuerdo con la sana crítica ${ }^{35}$. Así, exceptuando los peritajes, en los juicios relativos a responsabilidad médica y a responsabilidad asociada a desastres naturales -que son la muestra de este trabajo- los jueces tienen escaso margen de libertad en la apreciación de la prueba. La forma en que los tribunales chilenos han suplido esta escasa libertad en la apreciación de la prueba ha

34 Artículos 341 a 429 c.p.c. (título XI, libro II, "De los medios de prueba en particular") y artículos 1698 a 1714 c.c. (título xxi, libro IV, "De la prueba de las obligaciones").

35 Artículo 425 c.p.c.: "Los tribunales apreciarán la fuerza probatoria del dictamen de peritos en conformidad a las reglas de la sana crítica". 
sido mediante un amplio recurso a las presunciones judiciales ${ }^{36}$, aunque también es posible identificar algunas presunciones legales de causalidad.

La presunción es un tipo de razonamiento que permite al juez tener por acreditado un hecho desconocido -el nexo causal-sobre la base de un hecho conocido ${ }^{37}$. En la legislación chilena, esta forma de entender las presunciones se encuentra claramente acogida en el artículo 47 del código de Bello, que al efecto afirma: "se dice presumirse el hecho que se deduce de ciertos antecedentes o circunstancias conocidas", para luego dividirlas en presunciones legales y judiciales, y en simplemente legales y de derecho.

Coherentemente con ese planteamiento, en la justicia chilena, al igual que en el resto de los sistemas jurídicos, la prueba de la causalidad se puede articular mediante las presunciones legales o judiciales. En el primer supuesto, por ejemplo, la Ley n. ${ }^{\circ}$ 20.850 de 2015 sobre tratamientos médicos de alto costo estableció en el artículo 111 J que "en los ensayos clínicos, acreditado el daño, se presumirá que éste se ha producido con ocasión de la investigación”, un precepto que es típico del ámbito sanitario, tal como ocurre en Francia ${ }^{38}$; o bien, la disposición de la ley sobre medio ambiente del año 1994 (Ley n. ${ }^{\circ}$ 19.300), cuyo artículo 52 inciso 1. ${ }^{\circ}$ señaló que "se presume legalmente la responsabilidad del autor del daño ambiental, si existe infracción a las normas de calidad ambiental, a las normas de emisiones, a los planes de prevención o de descontaminación, a las regulaciones especiales para los casos de emergencia ambiental o a las normas sobre protección, preservación o conservación ambientales, establecidas en la presente ley o en otras disposiciones legales o reglamentarias".

La Corte Suprema aplicó esta última regla al acoger una demanda de daño ambiental por un derrame de petróleo en la bahía de Quintero (Región de Valparaíso), junto a la regla de la Ley de Navegación del año 1978 que "presume que el derrame o vertimiento de sustancias contaminantes del medio ambiente marino produce daño ecológico" (art. 144 n. ${ }^{\circ} 5$ DL n. ${ }^{\circ} 2222$ del Ministerio de Defensa) ${ }^{39}$. En concreto, la Tercera Sala de la Corte Suprema consideró que "un hecho causante" del daño ambiental "está constituido por el derrame de petróleo crudo en la bahía de Quintero el día 23 de septiembre de 2014" (cons. 23. ${ }^{\circ}$ ).

Sin embargo, al margen de estos casos, no existe una presunción legal de causalidad que sea de aplicación general en la ley civil chilena. No obstante, se ha discutido si una presunción de esta clase podría justificarse en virtud del artículo 2329

36 Hunter Ampuero, I., "Las dificultades probatorias en el proceso civil. Tratamiento doctrinal y jurisprudencial, críticas y una propuesta", Revista de Derecho, Universidad Católica del Norte, año 22, n. ${ }^{\circ} 1,209$ ss.

37 Cordopatri, F., s.v. "Presunzione (dir. proc. civ.)", Enciclopedia del diritto, vol. xxxv, Milano, Giuffrè, 1986, 274 ss.

38 Munita Marambio, R., "Causalidad incierta, alternativa y flexibilidad probatoria”, Bahamondes Oyarzún, C., Etcheberry Court, L. y Pizarro Wilson, C. (eds.), Estudios de derecho civil xiII, Santiago, Thomson Reuters, 2018, 745 ss.

39 Corte Suprema, 25 de septiembre de 2019, rol n. ${ }^{\circ} 13177-2018$. 
del código de Bello ${ }^{40}$, especialmente mediante la categoría del res ipsa loquitur, reconocida por la jurisprudencia chilena ${ }^{41}$.

En lo que atañe a las presunciones judiciales, en tanto, ellas son muy frecuentes, pues la ley procesal civil permite tener los hechos por probados cuando concurren presunciones con los caracteres de gravedad, precisión y concordancia ${ }^{42}$. Esta forma de razonamiento ha sido empleada explícitamente por la Corte Suprema en los juicios de responsabilidad civil relativos al 27F, en donde el déficit probatorio consiste en no saber si la persona que murió escuchó o no el anuncio radial del intendente de la región descartando el peligro de tsunami ${ }^{43}$.

En estos casos, la presunción judicial descansa en lo que normalmente hace una persona luego de un terremoto en una zona costera; dicha máxima de la experiencia (hecho conocido) le permite a la Corte Suprema tener por probado que las víctimas sí escucharon la transmisión radial en cuestión (hecho desconocido) puesto que no se movieron del lugar ${ }^{44}$. Con todo, aunque se aluda a la presunción, lo cierto es que esta forma de razonamiento aproxima a dos categorías diversas del derecho probatorio, la presunción judicial y la sana crítica, por cuanto la Corte Suprema se preocupa de establecer el elemento distintivo de una presunción, el "hecho base" o hecho conocido, mediante uno de los elementos de la sana crítica, la máxima de la experiencia.

En efecto, según la definición de presunción contenida en el código civil (art. 47), para que se configure una presunción judicial se requiere de "antecedentes o circunstancias conocidas" que le sirvan de base. De ahí que, tal como lo subraya la literatura angloamericana, en un sentido estricto solo se puede hablar de una presunción cuando hay un hecho conocido (o "hecho base") que ha sido debidamente probado en el juicio; en los demás casos se habla de inferencias, como es típico en un sistema de sana crítica ${ }^{45}$.

Así las cosas, las presunciones judiciales y la sana crítica tienen una semejanza y una diferencia específicas. En cuanto a su semejanza, ambas son formas de razo-

40 Artículo 2329 inciso $1 .^{\circ}$ c.c.: "Por regla general todo daño que pueda imputarse a malicia o negligencia de otra persona, debe ser reparado por ésta".

41 Larroucau Torres, J., “'Res ipsa loquitur': quien habla es el juez, no la cosa”, Figueroa, G., BARRos, E. y TAPIA M. (coords.), Estudios de derecho civil vi, Santiago, Legal Publishing, 2009, 491519.

42 Artículos 1712 c.c. y 426 c.p.c.

43 Es un hecho conocido que, aproximadamente a las 5 a. m. del día 27 de febrero, el intendente de la región del Biobío emitió una declaración radial descartando el peligro de tsunami, cuando en algunos lugares ya se había producido y en otros estaba próximo a producirse.

44 V. gr., Corte Suprema, 18 de diciembre de 2013, Rol n. ${ }^{\circ}$ 1629-2013, un análisis de este caso puede verse en SAN MARTín NeIRA, L., "Responsabilidad del Estado por falta de servicio 'Valenzuela Flores y otros con Fisco de Chile' (rol n. $\left.{ }^{\circ} 1629-2013\right)$ ", Roma e America, n. ${ }^{\circ} 34,2013,297-308$ y en LARA Arroyo, J. y García-Huidobro Herrera, L., “27F: ¿terremoto en la responsabilidad del Estado?, Anuario de Doctrina y Jurisprudencia. Sentencias destacadas 2013, Santiago, Libertad y Desarro1lo, 2014, 163-194.

45 Gama Leyva, R., Las presunciones en el derecho. Entre la perplejidad y la fascinación de los juristas, Valencia, Tirant lo Blanch, 240, 189-209. 
namiento judicial orientadas a un mismo fin: tener por probado un hecho sobre la base de parámetros de verificación externos al juez ${ }^{46}$, que en las presunciones se identifican con el "hecho base" previamente probado, mientras que en la sana crítica se identifican con la ciencia, la experiencia compartida y la lógica. La diferencia, en tanto, ya fue señalada: la sana crítica no precisa de un 'hecho base'. Una exigencia como esta solo se podría fundar en el deber general de motivar la sentencia definitiva.

De esa manera, en la medida en que los jueces utilizan como 'hecho base' de una presunción aquello que una persona razonable hubiera hecho en determinadas circunstancias -es decir, una máxima de la experiencia-, de facto aplican un sistema de valoración más cercano a la sana crítica y se apartan del mandato legal que les permite tener por probados los hechos mediante una presunción judicial, no a través de una valoración de acuerdo con la sana crítica.

\section{b. Estándares de prueba}

\section{- Estándares de prueba e incertidumbre causal}

Este criterio general para lidiar con la incertidumbre asume que la 'verdad' acerca de lo ocurrido es inalcanzable en un proceso judicial ${ }^{47}$. De allí que los estándares le informan al juez, en términos probabilísticos, acerca del grado de convicción necesario para tener por probado un hecho ${ }^{48}$, y son más o menos exigentes dependiendo de quién deba soportar el riesgo del error judicial.

Por tal razón, la dogmática, la jurisprudencia y algunas legislaciones son proclives a reconocer la existencia de estándares probatorios diferenciados en relación con el objeto del juicio. Así, por ejemplo, en los casos en que se discute la responsabilidad penal el estándar probatorio es más elevado en todas las jurisdicciones ya que se prefiere imponer al Estado (persecutor penal) el riesgo de error en lugar de condenar a un imputado inocente. En materia civil, en cambio, la cuestión varía según la jurisdicción.

En las jurisdicciones de common law el riesgo de error en los juicios civiles tiende a distribuirse entre las partes de acuerdo con un "balance de las probabilidades" 49 ,

46 Larroucau Torres, J., "Sana crítica y presunción judicial”, Revista de Derecho de la Universidad de Concepción, $\mathrm{n} .^{\circ}$ 238, 7-36.

47 Ferrer Beltrán, J., La valoración racional de la prueba, Madrid, Marcial Pons, 2007, 20. Véase

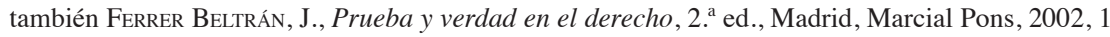
ss.; TARUfFo, M., "La prueba científica en el proceso civil", FerRer, J. et al., Estudios sobre prueba, México, Universidad Nacional Autónoma de México, 2011, 48 ss.; Papayannis, D., Causalidad y atribución, cit., 113 ss.

48 Por todos, Larroucau Torres, J., "Hacia un estándar de prueba civil”, Revista Chilena de Derecho, vol. 39, n. $^{\circ} 3,2012,783-808$.

49 Oliphant, K., "Causal uncertainty and proportional liability in England and Wales", en GilEad, I., Green, M. у Косн, B. (eds.), Proportional Liability: Analitical and Comparative Perspectives, Berlin-Boston, De Gruyter, 2013, 121. 
de modo que el estándar se corresponde con el 50\% más uno de probabilidades (more likely than not o more probable than not) de que la conducta del demandado haya ocasionado el daño ${ }^{50}$. En los ordenamientos jurídicos de tradición continental, en cambio, estos estándares oscilan desde uno cercano a la certeza -como ocurre en Alemania ${ }^{51}$, Francia ${ }^{52}$ y España ${ }^{53}$ - al estándar de "más probable que no" (più probabile che non) que apela al $50 \%$ más uno de probabilidades, como ocurre en el ordenamiento jurídico italiano ${ }^{54}$. Naturalmente, entre más alto el estándar, más gravosas son las exigencias probatorias que enfrenta la víctima. Sin embargo, la premisa es siempre la misma: el nexo de causalidad entre la conducta del agente y el daño se demuestra sin que se requiera una absoluta certeza de que el daño no se habría verificado sin dicha condición ${ }^{55}$.

En el caso chileno, en particular, no existen reglas legales que se refieran a los estándares de prueba, salvo en materia penal, en donde se introdujo el estándar de "más allá de toda duda razonable" con el código procesal penal del año 2000 (art. 340). Lo más cercano a un estándar de prueba que utilizan los jueces civiles es su 'convicción' en torno a la verdad de los hechos en que se basa la sentencia. Con todo, la Corte Suprema ha razonado sobre el hecho de que, en algunos casos, el estándar de prueba no puede ser "extremado".

Así, en las demandas en contra del Estado a raíz del tsunami del 27F se discutió si las víctimas efectivamente escucharon el anuncio del intendente de la Región del Bío Bío que cancelaba la alerta de tsunami y llamaba a la población a permanecer en sus hogares ${ }^{56}$, o bien, si las personas que murieron a causa del mismo tsunami,

50 Green D., M., "Causal uncertainty and proportional liability in the US", en GILEAD, I., GreEn, M. y Koch, B (eds.), Proportional Liability: Analitical and Comparative Perspectives, cit, 243.

51 Magnus, U., "Causal uncertainty and proportional liability in Germany", Gilead, I., GreEn, M. y Косн, B (eds.), Proportional Liability: Analitical and Comparative Perspectives, cit., 158.

52 Moréteau, O., "Causal uncertainty", cit., 142.

53 Martín-Casals, M. y Solé, J., "Causal uncertainty and proportional liability in Spain”, en Gilead, I., Green, M. y Koch, B. (eds.), Proportional Liability, cit., 295. Con todo, alguna doctrina española hace ver que en ciertos casos el Supremo Tribunal Español ha aplicado el criterio del más probable que no. Así, a propósito del conocido caso del aceite de colza, Múrtula Lafuente, V., "Causalidad alternativa", cit., 17. A su vez, existe quien opina que en España el estándar probatorio es justamente el de la "probabilidad preponderante", es decir, 50\% más uno. En este sentido Medina Alcoz, L., La responsabilidad proporcional como solución a la incertidumbre causal, Madrid, Civitas-Thomson Reuters, 2018, 28 ss.

54 Cass. Civ. Sez. III, 9 de junio de 2011, n. ${ }^{\circ}$ 12686, consultada en Danno e responsabilità, 6, 2013, 638. Esta idea constituye prácticamente un "considerando de estilo" en la casación italiana. TASSONE, B., "Concause, orientamenti recenti e teorie sulla causalità", Danno e responsabilità, 6, 2013, 633-660, especialmente $649, \mathrm{n} .^{\circ} 1$.

55 Gilead, I., Green, M. D. y Koch, B. A., "General Report. Causal uncertainty and proportional liability: analytical and comparative report”, en Gilead, I., Green, M. y Koch, B. (eds.), Proportional Liability: Analitical and Comparative Perspectives, cit., 21.

56 V. gr., Corte Suprema, 18 de marzo de 2019, rol n. ${ }^{\circ} 4185-2018$; Corte Suprema, 12 de diciembre de 2017, rol n. ${ }^{\circ}$ 172-2017; Corte Suprema, 28 de agosto de 2017, rol n. ${ }^{\circ}$ 97661-2016; Corte Suprema, 4 de octubre de 2016, rol n. ${ }^{\circ}$ 24306-2016; Corte Suprema, 29 de abril de 2014, rol n. ${ }^{\circ} 16885-2013$; 
de haber sido avisadas por las autoridades, habrían tenido oportunidad de ponerse a resguardo ${ }^{57}$. En la misma línea, también se ha discutido si acaso la autoridad hubiese diseñado planes de contingencia para zonas altamente expuestas al riesgo de tsunami y educado a la población que se encontraba en esos lugares, no hubiesen muerto todas o algunas de las personas luego del tsunami ${ }^{58}$.

En tales casos la jurisprudencia chilena ha acogido las demandas mediante un juicio de probabilidad que considera suficientemente demostrado que, si el demandado hubiese actuado de otra manera, el daño no se habría producido. Con todo, este razonamiento no es explícito, pues los tribunales no aluden al grado de probabilidad, sino que se limitan a señalar que en circunstancias como estas no puede exigirse una absoluta certeza judicial. Así, a propósito de un caso en el que no estaba claro si una víctima del tsunami había verdaderamente escuchado el anuncio radial que llamaba a quedarse en casa, resultando incluso discutido el lugar específico en donde la había encontrado la honda, la Corte Suprema sostuvo:

Además de no dejar explicado el fundamento de semejante enunciado, es el parecer de esta Corte que no se aviene con el sentido común extremar la carga probatoria en circunstancias tan caóticas como las que -conocimiento adquirido- sucedieron a las catástrofes, como si entonces estuvieran dadas las condiciones para documentación burocrática propia de tiempos normales ${ }^{59}$.

En materia médica, en cambio, el razonamiento judicial es un poco más explícito en cuanto al uso de las probabilidades para lograr el convencimiento judicial. Así, por ejemplo, la Corte Suprema ha resuelto:

... en materia sanitaria la certidumbre sobre la relación causal es difícil de establecer, por lo que en estos regímenes de responsabilidad en la mayoría de los casos sólo será posible efectuar una estimación de la probabilidad de que el daño se deba a un hecho o, al incumplimiento de un deber de atención eficaz y eficiente, por el cual el demandado deba responder ${ }^{60}$.

Corte Suprema, 29 de abril de 2014, rol n. ${ }^{\circ}$ 16920-2013; Corte Suprema, 18 de diciembre de 2013, rol n. ${ }^{\circ}$ 1629-2013; Corte Suprema, 23 de enero de 2013, rol n. ${ }^{\circ} 1250-2012$;

57 Corte Suprema, . $^{\circ}$ de febrero de 2019, rol n. ${ }^{\circ}$ 3033-2018; Corte Suprema, 31 de julio de 2017, rol n. ${ }^{\circ}$ 88986-2016; Corte Suprema, 9 de noviembre de 2017, rol n. ${ }^{\circ}$ 12169-2017; Corte Suprema, 7 de junio de 2016, rol n. ${ }^{\circ} 32262-2015$.

58 Corte Suprema, 17 de abril de 2018, rol n. ${ }^{\circ}$ 18225-2017; Corte Suprema, 17 de enero de 2018, rol n. 5094-2017; Corte Suprema, 16 de noviembre de 2017, rol n. ${ }^{\circ} 4658-2017$; Corte Suprema, 21 de enero de 2019, rol n. ${ }^{\circ}$ 40166-2017; Corte Suprema, 17 de abril de 2018, rol n. ${ }^{\circ}$ 18225-2017.

59 Corte Suprema, 18 de diciembre de 2013, rol n. ${ }^{\circ} 1629-2013$.

60 Corte Suprema, 3 de septiembre de 2018, rol n. ${ }^{\circ} 826-2018$. 
Sin embargo, no se visualiza un intento por individualizar cuál sería el grado de probabilidad aceptable para tener por acreditado el nexo causal.

\section{- Estándares de prueba y funciones de la causalidad}

Es importante señalar que las dos funciones de la causalidad mencionadas en la primera distinción de este artículo -como fundamento y como límite de la responsabilidad civil- también son relevantes a la hora de fijar los estándares de prueba. Así, por ejemplo, en el ordenamiento alemán, el umbral exigido para dar por acreditado el vínculo causal como fundamento de la responsabilidad (haftungsbegründende Kausalität) es el "más allá de toda duda razonable", mientras que para probar la causalidad como límite (haftungsausfüllende Kausälitat) se emplea el estándar de la probabilidad preponderante ${ }^{61}$.

En el derecho chileno, en tanto, aunque no hay una referencia expresa sobre el punto, estimamos que también se puede justificar el empleo de estándares probatorios diferentes para la prueba de la causalidad dependiendo de sus funciones. Esta diferencia se funda en el hecho de que la determinación del monto del daño se puede reservar para la fase de cumplimiento del fallo (art. 173 c.p.c.), en donde las exigencias probatorias son menores que durante el procedimiento declarativo en que el tribunal se pronuncia sobre la causalidad como fundamento de la responsabilidad civil.

En efecto, de acuerdo con la ley procesal civil chilena, si una parte debe ser condenada a la devolución de frutos o a la indemnización de daños (ya sea en juicios de responsabilidad contractual, extracontractual o legal ${ }^{62}$ ) es necesario distinguir lo siguiente (art. 173 c.p.c.): (1) si se ha litigado sobre su especie y monto, la sentencia debe determinar la cantidad líquida a pagar o bien declarar sin lugar el pago si no se probaron la especie y el monto de lo que se cobra o al menos las bases que deban servir para su liquidación al ejecutarse la sentencia; pero, (2) si no se litigó sobre la especie y el monto de los frutos o perjuicios, el tribunal reserva a las partes el derecho de discutir esta cuestión en la ejecución del fallo, o bien en otro juicio diverso (art. 173 c.p.c.) ${ }^{63}$. En este nuevo juicio -que solo es tal cuando se ha reservado el debate sobre el monto de los daños para la fase de ejecución- es posible rebajar las exigencias probatorias de la causalidad como límite de la indemnización, ya que ella fue probada como fundamento durante el juicio declarativo previo.

61 Magnus, U., "Causal uncertainty”, cit., 160.

62 Domínguez Águila, R., "Comentario de jurisprudencia. Reserva del derecho a discutir la especie y monto de los perjuicios", Revista de Derecho de la Universidad de Concepción, n. ${ }^{\circ} 206,1999$, 169-174; Domínguez Águlla, R., "Comentario de jurisprudencia. Reserva del derecho a discutir los daños. Art. 173 del código de procedimiento civil", Revista de Derecho de la Universidad de Concepción, $\mathrm{n} .^{\circ} 214,2003,186-188$ (afirma que la regla se restringe solo a la responsabilidad contractual).

63 El Proyecto de Código Procesal Civil del año 2012 (Boletín n. ${ }^{\circ}$ 8197-07) denominó a estos últimos casos una sentencia de condena genérica (art. 208). 
Así ocurre, por lo demás, en la litigación ambiental, en donde, una vez establecido el daño ambiental, la acción de indemnización de perjuicios se tramita en una audiencia de contestación, conciliación y prueba "que versará sobre la existencia, naturaleza y monto de los perjuicios, sobre la relación causal entre los perjuicios y el daño ambiental establecido por el Tribunal Ambiental y sobre las otras defensas que el demandado pudiere alegar, con exclusión de aquellas vinculadas a la inexistencia de un ilícito o de culpabilidad, que se considerarán hechos establecidos por la sentencia del Tribunal Ambiental" (art. 46 n..$^{\circ} 1$ y 2 Ley n..$^{\circ} 20.600$ de 2012). En otras palabras, en este juicio civil solo se discute sumariamente la causalidad como límite de la responsabilidad para fijar el monto a indemnizar. Es por este motivo que la ley agrega que "el tribunal civil competente, al resolver sobre la indemnización de perjuicios se basará en el daño ambiental y la relación causal entre éste y la acción del ofensor establecidas por el Tribunal Ambiental" (art. 46 inc. 2. ${ }^{\circ}$ Ley n. ${ }^{\circ} 20.600$ ).

\section{Criterios especiales}

Según se ha demostrado, la incertidumbre que caracteriza a la prueba judicial de la causalidad genera un déficit epistémico o bien un déficit probatorio, lo que abre un debate sobre la distribución del riesgo de error entre demandante y demandado. Este reparto del riesgo de error ha llevado al diseño de una serie de mecanismos jurídicos que persiguen resolver problemas de prueba de la causalidad. La mayoría de estos mecanismos busca sortear el déficit probatorio, tal como se ha visto que ocurre con las presunciones, la sana crítica y los estándares de prueba, pero algunos de ellos, como la pérdida de oportunidad, abordan directamente el déficit epistémico.

En tal sentido, son particularmente destacables las soluciones aplicables a casos en que es posible y probable que el demandado sea el causante del daño pero dicha probabilidad no es concluyente, pues hay otras condiciones que pueden explicarlo, y que a nivel comparado han dado origen a la llamada "responsabilidad proporcional" 64 , cuyas principales manifestaciones son la responsabilidad por mercado compartido, la pérdida de oportunidad y el aumento de riesgo ${ }^{65}$.

64 Sobre el particular, GREEN, S., "The risk pricing principle: a pragmatic approach to causation and apportionment of damages", Law, Probability and Risk, n. ${ }^{4}$, 2005, 161-162; MarTín-CASALs, M., "Proportional liability in Spain. A bridge too far?", en Martín-Casals, M. y Papayannis, D. (eds.), Uncertain Causation in Tort Law, Cambridge, Cambridge University Press, 2016, 43-66; Косн, B., "Proportional liability for causal uncertainty. How to works on the basis of a 200-year-old code", ibíd., 67-86; Gilead, I., Green, M. y Koch, B. (eds.), "General Report. Causal uncertainty and proportional liability: analytical and comparative report", cit., 5 .

65 Un análisis crítico de esta doctrina, entendida como el aumento del riesgo a más del doble, que es la forma en que surge en los Estados Unidos de Norteamérica, puede verse en HAACK, S., "Asuntos arriesgados: sobre la prueba estadística de la causación específica”, en PAPAYANnIs, D., Causalidad y atribución de responsabilidad, Madrid, Marcial Pons, 2014, 103 ss. 
La teorización de la responsabilidad proporcional ha sido principalmente fruto de la literatura de common law ${ }^{66}$, sobre todo estadounidense ${ }^{67}$, pero también ha entrado en la órbita del sistema continental ${ }^{68}$. En Chile, sin embargo, no se registran por ahora estudios que aborden el argumento desde esta perspectiva, aunque sí es posible advertir la presencia clara de una de sus variantes: la pérdida de oportunidad.

En la misma línea, la literatura sobre prueba judicial ha elaborado la teoría del daño probatorio, según la cual un litigante puede sufrir un daño consistente justamente en la imposibilidad de acceder a la prueba que requiere para demostrar un hecho como la causalidad. Al igual que ocurre con la responsabilidad proporcional, se trata de un criterio jurídico aglutinador de varias manifestaciones de la incertidumbre causal, entre ellas la pérdida de oportunidad. A pesar de que en Chile no se le ha reconocido con este nombre, es posible identificar algunas sentencias que calzan completamente con esta teoría.

\section{a. Pérdida de la oportunidad}

Este criterio se hace cargo del déficit epistémico derivado del hecho de que el caso concreto presenta un alea que introduce una variable insuperable en términos probatorios y, por consiguiente, el test de conditio sine qua non está inexorablemente destinado a fracasar. Para evitar el rechazo de todas las demandas en los casos que presentan esta característica, se introduce una suerte de excepción a la regla "todo o nada", que rige en los procesos de responsabilidad civil, y se otorga a la víctima una indemnización limitada ${ }^{69}$. Existiendo dos alternativas para la determinación del quantum indemnizatorio: en la primera se valora la chance en sí misma, considerando su pérdida como un daño autónomo; en la segunda, en cambio, se indemniza un porcentaje del daño real sufrido (esto es, la frustración de la ventaja que se esperaba obtener) de acuerdo con las probabilidades de que efectivamente se hubiese obtenido dicha ventaja de no haber mediado la conducta del demandado.

De esa manera, aunque no siempre se diga, la pérdida de oportunidad se presenta como una especie de responsabilidad proporcional en "favor de la víctima"70,

66 WeIR, Tony, “All or nothing?”, Tulane Law Review, 2003-2004, 78, 2004, 511-552; GreEn, M., "The future of proportional liability", en Stuart, M. (ed.), Exploring Tort Law, Cambridge, Cambridge University Press, 2005, 352-400; GREEN, S., "The risk pricing principle”, cit., 159-175; LESHEM, S. y Miller, G., "All-or-nothing versus proportionate damages", Journal of Legal Studies, Universidad de Chicago, vol. 38, 2009, 345-382.

67 Con abundantes citas al respecto, GreEn D., M., "Causal uncertainty”, cit., 343 ss.

68 Gilead, I., Green, M., Koch, B. (eds.), Proportional Liability: Analytical and Comparative Perspectives, Tort and Insurance Law, vol. 33, Berlin-Boston, De Gruyter, 2013; Medina Alcoz, L., La responsabilidad proporcional como solución a la incertidumbre causal, Madrid, Civitas-Thomson Reuters, 2018.

69 Nocco, L., "Causalità: dalla probabilità logica (nuovamente) alla probabilità statistica, la Cassazione civile fa retromarcia", Danno e responsabilità, n. ${ }^{\circ}$ 12-2006, 1244.

70 Sobre el particular, Gilead, I., Green, M. y Kосн, B., "General Report”, cit., 39 ss. 
quien obtendrá alguna indemnización ${ }^{71}$, a pesar de que no es posible establecer, conforme al estándar de convicción vigente en el ordenamiento, que la conducta del demandado fue determinante en el resultado nocivo.

En Chile, luego de haber sido ampliamente defendido por la doctrina ${ }^{72}$, este criterio irrumpió con fuerza en la jurisprudencia sobre responsabilidad médica ${ }^{73}$ y en las sentencias por los casos del $27 \mathrm{~F}^{74}$. En ambos casos, los tribunales han reconocido que la aplicación de esta doctrina se debe a las dificultades probatorias que enfrentan los demandantes. A modo de ejemplo, cabe citar el razonamiento de la Corte Suprema en Sepúlveda con Fisco de Chile, en donde expresamente se indica:

Si bien la certidumbre sobre la relación causal es difícil de establecer, tal dificultad se hace más evidente en estos regímenes de responsabilidad en que, en la mayoría de los casos, sólo será posible efectuar una estimación de la probabilidad de que el daño se deba a un hecho u omisión por el cual el demandado deba responder. En la situación que nos ocupa existen, por cierto, dificultades y determinados grados de incertidumbre para establecer de modo fehaciente el vínculo causal; sin embargo, este escollo se soslaya al atender a las circunstancias que generan la responsabilidad, esto es a la omisión en comunicar la alerta de tsunami y, no menos importante que lo anterior, al haber descartado los funcionarios de turno de la Armada acciones de rescate, habiéndoles sido expresamente solicitado el servicio. Es de esta forma que, acertadamente, los sentenciadores acuden a la teoría de la pérdida de la chance ${ }^{75}$.

71 En este sentido, TASSONE, B., "Solidarietà e parziarietà nell'ordinamento italiano, un'analisi operazionale", Danno e responsabilità, n. ${ }^{\circ}$ 11-2007, 1108; Nocco, L., "Rilevanza delle concause naturali e responsabilità proporzionale: un discutibile revirement della Cassazione", Danno e responsabilità , 2, 2012, 161; Medina Alcoz, L., La responsabilidad proporcional, cit., passim. Incluso en Francia, donde la doctrina y la jurisprudencia están acordes en que la pérdida de chance es una partida autónoma de daño, es posible observar opiniones en este sentido; véase, p. ej., Moréteau, O., "Causal uncertainty", cit., 143 y 144.

72 Por todos, Ríos, I. y Silva, R., Responsabilidad civil por pérdida de la oportunidad, Santiago, Jurídica de Chile, 2014; BARRía DíAz, R., "La pérdida de una oportunidad en la jurisprudencia de la Corte Suprema sobre juicios indemnizatorios derivados del terremoto y tsunami de 27 de febrero de 2010”, Revista de Derecho Universidad de Concepción, n. ${ }^{\circ} 245$, 2018, 235-269; Mejías Alonzo, C. "Pérdida de una chance. Una revisión a partir de los requisitos del daño indemnizable", GómEZ DE LA Torre Vargas, M. et al. (eds.), Estudios de derecho civil XIV, Santiago, Thomson Reuters, 2019, 1067 ss.

73 V. gr., Corte Suprema, 3 de diciembre de 2015, rol n. ${ }^{\circ}$ 29365-2014; Corte Suprema, 22 de septiembre de 2016, rol n. ${ }^{\circ}$ 9481-2016; Corte Suprema, 25 de octubre de 2016, rol n. ${ }^{\circ}$ 22751-2015; Corte Suprema, 26 de diciembre de 2017, rol n. ${ }^{\circ}$ 118-2017; Corte Suprema, 25 de julio de 2018, rol n. ${ }^{\circ}$ 30264-2017; Corte Suprema, 2 de octubre de 2018, rol n. ${ }^{\circ} 41890-2017$; Corte Suprema, 24 de abril de 2019 , rol n. ${ }^{\circ} 7108-2017$.

74 V. gr., Corte Suprema, 16 de noviembre de 2017, rol n. ${ }^{\circ} 4658-2017$; Corte Suprema, 17 de enero de 2018, rol n. ${ }^{\circ}$ 5094-2017; Corte Suprema, 17 de abril de 2018, rol n. ${ }^{\circ}$ 18225-2017; Corte Suprema, 14 de agosto de 2019 , rol n. ${ }^{\circ} 2456-2018$.

75 Cfr. Corte Suprema, 14 de agosto de 2019, rol n. ${ }^{\circ} 2456-2018$. 
De esta manera, la pérdida de oportunidad configura un mecanismo de facilitación probatoria para los demandantes, quienes se encuentran en la imposibilidad de acreditar que la causa específica de la muerte de sus seres queridos fue la falta de servicio del Estado $^{76}$.

La misma idea se encuentra plasmada en los fallos que acogen la pérdida de chance en responsabilidad médica, donde se reconoce que este mecanismo es un paliativo frente a la imposibilidad de establecer si el daño invocado se habría producido igualmente en ausencia de la acción negligente del demandado, lo que equivale a que no es posible establecer si la causa específica del daño es la negligencia médica o bien la enfermedad que ya aquejaba al paciente ${ }^{77}$.

Con todo, la jurisprudencia nacional no se ha hecho cargo del hecho de que la pérdida de oportunidad constituye un paliativo al déficit epistémico y no una fórmula para suplir la ausencia de información en aquellos casos en que hay solo un déficit probatorio que el litigante que tiene la carga de la prueba debe superar. Con lo cual existe el riesgo de una sobreutilización de la herramienta y de una tergiversación de su finalidad.

\section{b. Daño probatorio}

El "principio del daño probatorio" (evidential damage principle) ha sido diseñado como un criterio aglutinador para abordar la prueba judicial de los hechos bajo circunstancias de incertidumbre. Esta tesis fue propuesta por Ariel Porat y Alex Stein a fines de los años noventa. El fundamento de su interpretación es que las conductas de una persona pueden provocar incerteza a la contraria con respecto de la fijación de los hechos, esto es, un déficit probatorio. Se trata, por tanto, de una especie de responsabilidad civil por incertidumbre ${ }^{78}$.

Esta teoría comprende aquellos escenarios que se materializan fuera de un proceso judicial, sobre todo a raíz de conflictos de responsabilidad-como la pérdida de oportunidad y la imputación con base en el mercado compartido-, laborales -la discriminación positiva ante despidos injustificados- y de contratación civil -interpretar una cláusula confusa o dudosa en beneficio de quien no la redactó-. Todos estos casos serían manifestaciones desarticuladas de lo que Porat y Stein llaman el "daño

76 Para un análisis detallado las sentencias relativas al 27F que aplican la pérdida de oportunidad, BARría DíAz, R., "La pérdida de una oportunidad”, cit., 235-269.

77 Para un análisis detallado de esta jurisprudencia, Cárdenas Villarreal, H. A. "La pérdida de la chance en la reciente jurisprudencia médica", Gómez de LA Torre VARGAS, M. et al. (eds.), Estudios de derecho civil XIV, Santiago, Thomson Reuters, 2019, 1027 ss.

78 Porat, A. y Stein, A., "Liability for uncertainty: making evidential damage actionable", Cardozo Law Review, vol. 18, 1997, 1941-1960; Porat, A. y Stein, A., Tort Liability under Uncertainty, Oxford, Oxford University Press, 2001, 160-184; PorAT, A. y STEIn, A., "Indeterminate causation and apportionment of damages: an essay on Holtby, Allen, and Fairchild", Oxford Journal of Legal Studies, vol. 23, n. ${ }^{\circ}$ 4, 2003, 667-702. 
probatorio" sufrido por un litigante ${ }^{79}$. Así, por ejemplo, formaría parte del repertorio de esta teoría la ley que dispone que se presume dolo en el caso de que alguien haya "detenido u ocultado" un testamento (art. 968 n. 5 c.c.) ya que ello impide conocer la voluntad del causante.

En cuanto a su diseño, esta propuesta solo cubre la hipótesis en que el medio de prueba se oculta o se destruye intencionalmente (según la máxima "nadie puede obtener provecho de su propio dolo" 80 ), pero nada dice respecto de los casos en que la prueba falta por otras razones. Con todo, la tesis de Porat y Stein en relación con el "daño probatorio" sí permite explicar que la destrucción de pruebas o la reticencia a contribuir en el conocimiento del caso por parte del demandado siempre son decisiones que afectan la autonomía de una persona en la medida en que le impiden evaluar si debe o no judicializar su conflicto y en qué términos hacerlo.

En definitiva, este criterio jurídico específico permite abordar varios escenarios en donde el riesgo de error al decidir qué hechos se han probado no es recíproco entre las partes, ya que una lo genera (y obtiene provecho de ello) y la otra lo padece. Esta asimetría entre las partes es la que explica, por ejemplo, que si un transeúnte mira hacia otra parte en el momento preciso en que ocurre un accidente vehicular no le provoca a la víctima un "daño probatorio", como sí lo hace quien introduce en el mercado un producto sin la información necesaria para el consumidor, o bien cuyos efectos secundarios no han sido testeados en la forma debida ${ }^{81}$. Para enfrentar estos casos, Porat y Stein proponen dos alternativas: (1) imponer la carga de la prueba como regla de juicio a quien ha provocado el "daño probatorio" cuando dicha persona es al mismo tiempo el autor de los perjuicios directos (p. ej., el empleador que no entrega el contenido de una cámara de seguridad que grabó el accidente del trabajador), o bien (2) la indemnización del perjuicio causado por no acceder al medio de prueba si el "daño probatorio" lo ocasiona un tercero.

En este segundo caso, el "daño probatorio" justifica imponer la obligación de pagar el monto de la información que ya no está disponible, cuyo valor se deriva estadísticamente de su potencial para establecer la hipótesis de esta parte. Esto exige multiplicar el monto del daño directo por la probabilidad de que el demandado sea el causante del perjuicio.

En Chile, un escenario de este tipo se produjo en el caso Hagan con Fisco, caso que, si bien se resolvió invocando la pérdida de oportunidad, contiene todos los elementos que permiten afirmar un daño probatorio precisamente porque la pérdida de oportunidad es una de las expresiones más conocidas de esta teoría probatoria. En efecto, en el caso Hagan, el Tercer Juzgado Civil de Temuco acogió la demanda de indemnización de daños interpuesta en contra de la Policía de Investigaciones

79 Porat y SteIn, "Liability for uncertainty", cit., 1896-1900.

80 STEIN, A., "The refoundation of evidence law", Canadian Journal of Law \& Jurisprudence, vol. 9, 340 y Stein, A., Foundations of Evidence Law, Oxford, Oxford University Press, reimp., 2008, 167-171.

81 Porat, A. y Stein, A., "Liability for uncertainty", cit., 1923-1926. 
(PDI) por la deficiente investigación del homicidio de la hija de la demandante ${ }^{82}$. En el caso, se probó que al desarrollar su labor la PDI contaminó el lugar del crimen y el arma homicida, perdió el reloj de la víctima y permitió un ingreso que no era necesario (de bomberos) una vez asegurado el lugar. Estas circunstancias llevaron al tribunal a establecer:

... de haber cumplido el órgano investigativo policial con sus obligaciones y prestado debidamente el servicio a que se encuentra obligado, si bien, no es posible asegurar éxito total en la determinación del o los responsables del homicidio de la hija del actor, con la falta de servicio, se ha desvanecido o derechamente eliminado dicha posibilidad, existiendo en consecuencia relación de causalidad entre la falta de servicio y el daño sufrido por el actor" (cons. $31 .^{\circ}$ ).

Esta decisión no solo fue confirmada por la Corte de Temuco sino que, en un fallo dividido, hizo extensiva la responsabilidad civil al Ministerio Público, órgano encargado de la persecución penal, justamente por haber desperdiciado "la prueba más importante obtenida en la causa" (cons. $\left.11 .^{\circ}\right)^{83}$.

Este fallo fue confirmado por la Corte Suprema, la cual también esgrimió el criterio de la pérdida de la oportunidad, que es tributario de la teoría del daño probatorio. De acuerdo con el razonamiento de la Tercera Sala de este tribunal, los demandados le ocasionaron a la víctima "la pérdida de una mejor posición al enfrentar el juicio penal oral sobre el homicidio de su hija, de modo que de no haber mediado las acciones y omisiones culpables de los demandados, habría podido obtener una declaración judicial de responsabilidad o bien, su posición frente al juicio habría sido mejor que aquella que resultó en definitiva" 84 .

\section{Conclusiones}

Este trabajo demuestra que las tres distinciones más importantes a propósito de la causalidad tienen relevancia a efectos del razonamiento probatorio judicial relativo a este elemento de la responsabilidad civil, lo que es particularmente evidente en casos con incertidumbre causal elevada. En particular, este artículo hace énfasis en el he-

82 Tercer Juzgado Civil de Temuco, rol n. ${ }^{\circ}$ 4458-2016, 29 de diciembre de 2017.

83 Corte de Apelaciones de Temuco, 7 de mayo de 2019, rol n. ${ }^{\circ}$ 112-2018. La Corte de Temuco sostuvo que dicha prueba "fue el atizador con el cual se cometió el crimen el cual contenía rastros de ADN del imputado [...] y de otra persona no identificada, prueba que fue contaminada por la Policía de Investigaciones al momento de ser levantada como evidencia material en el sitio del suceso, que fue contestada por la defensa en juicio al no contar el Ministerio Público con un electroferograma[,] lo que si bien, no es habitual que se exija, está dentro de las facultades de los Tribunales del Juicio Oral en lo Penal" (cons. 11. ${ }^{\circ}$ ); y, además, que el "no haber adoptado medidas tendientes a asegurar las evidencias del hecho, como el reloj de [la víctima], una pertenencia personal, lo hacen también responsable por un actuar negligente carente de justificación" (cons. 12..$^{\circ}$ ).

Corte Suprema, 9 de marzo de 2020, rol n. ${ }^{\circ}$ 17405-2019. 
cho de que la distinción entre causalidad material y causalidad jurídica se difumina en la práctica judicial, en la medida en que -en cuanto fundamento de la responsabilidad civil- la causalidad suele acreditarse recurriendo a criterios jurídicos.

De esta manera, es posible afirmar que el juez tiene dos estrategias para decidir acerca de la causalidad en los juicios de responsabilidad civil con incertidumbre causal elevada. La primera de ellas se funda en la conexión funcional entre culpa y causalidad, cuyas raíces históricas son claras y que ha sido reconocida tanto en algunas disposiciones legales del ordenamiento jurídico chileno como en su jurisprudencia civil, y la cual consiente en que, en presencia de dos condiciones necesarias para la ocurrencia del daño, se considere 'causa' a la condición culpable. Así las cosas, en una buena parte de los casos, la prueba de la causalidad -en cuanto fundamento de la responsabilidad-se condice con la prueba de la culpa. En el caso de la responsabilidad médica, por ejemplo, el nexo causal entre el actuar médico y el daño sufrido por el paciente queda demostrado cuando se acredita la infracción a la lex artis; mientras que en los casos de responsabilidad por desastres naturales solo se rechaza la demanda aduciendo que el desastre es un caso fortuito en la medida en que no esté acreditada la culpa del demandado.

En síntesis, en los juicios de responsabilidad civil fundados en la negligencia del agente, el razonamiento judicial discurre del siguiente modo: si la víctima prueba una causalidad genérica con un grado de probabilidad suficiente gracias a elementos de juicio tales como estudios epidemiológicos, estudios in vitro o in vivo u otras generalizaciones estadísticas y, a su vez, está acreditada la negligencia del agente, estas circunstancias permiten tener por probado el nexo de causalidad a nivel de causalidad específica.

En los casos en que la conexión funcional entre culpa y causalidad no es suficiente adquieren relevancia otros criterios normativos, distintos de la culpa, algunos de los cuales tienen el carácter de generales, en tanto están dados para solventar déficits probatorios de cualquier índole (como las presunciones, la sana crítica y los estándares de prueba), mientras que otros tienen el carácter de particulares, en tanto han sido diseñados específicamente para enfrentar casos de incertidumbre causal elevada (la pérdida de la oportunidad y el daño probatorio). En estos últimos casos cabe destacar el hecho de que la pérdida de oportunidad es un mecanismo diseñado para abordar directamente el déficit epistémico que caracteriza a aquellos juicios en que, debido a la presencia de un alea, el test de conditio sine qua non está destinado inexorablemente a fracasar.

La jurisprudencia chilena de las últimas dos décadas, de manera más o menos directa y sistemática, hace uso de todos los criterios recién mencionados. Así, recurre asiduamente a las presunciones, aunque no siempre respetando su estructura sino acercándose más bien a un sistema de sana crítica, dado que no siempre establece el hecho base de la presunción. En esa misma línea, en los últimos años es posible observar un contundente uso de la doctrina de la pérdida de oportunidad, aunque sin advertir que se trata de un mecanismo destinado a solventar déficits epistémicos y no 
probatorios. Por su parte, en lo relativo a los estándares de prueba, la jurisprudencia civil chilena no se ha hecho cargo de definir cuál es el estándar de prueba que rige en el ordenamiento nacional, encontrándose solo alusiones generales al punto, en términos de convicción judicial. Finalmente, aunque de forma velada, ha sido reconocida también la teoría del daño probatorio, en la medida en que es posible encontrar sentencias reconducibles a esta doctrina, bajo la idea de pérdida de oportunidad.

\section{Referencias}

Accattino Scagliotti, D., "Incertidumbre, probabilidad y prueba de la causalidad en el derecho de daños. Análisis de la doctrina del incremento del riesgo a más del doble", Marín, J. y Schopf Olea, A. (eds.), Lo público y lo privado en el derecho. Estudios en homenaje al profesor Enrique Barros Bourie, Santiago, Thomson Reuters, 2017.

Aedo Barrena, C., "La cuestión causal en la 'lex Aquilia' y su solución mediante el mecanismo de la culpa", Revista de Estudios Histórico-Jurídicos, Valparaíso, n. ${ }^{\circ}$ XXXVII, 2015.

BANFI DEL Río, C., "La causalidad en casos de responsabilidad civil por mesotelioma: una mirada al derecho chileno e inglés", Marín, J. y Schopf Olea, A. (eds.), Lo público y lo privado en el derecho. Estudios en homenaje al profesor Enrique Barros Bourie, Santiago, Thomson Reuters, 2017.

BANFI DEl Río, C., "Relevancia del dolo en la responsabilidad extracontractual chilena: una relectura desde el derecho inglés", Revista de Derecho Universidad Católica del Norte, 2017.

Barría DíAz, R., "La pérdida de una oportunidad en la jurisprudencia de la Corte Suprema sobre juicios indemnizatorios derivados del terremoto y tsunami de 27 de febrero de 2010", Revista de Derecho Universidad de Concepción, n. . 245 , 2018.

Barros Bourie, E., Tratado de responsabilidad civil extracontractual, Santiago, Jurídica de Chile, 2006.

Corte Suprema di Cassazione italiana. Cassazione Civile, Sentenza III, 9 de junio de 2011, n. $^{\circ} 12686$.

CAne, P., "Responsibility and fault: a relational and functional approach to responsibility”, en CANE, P. y GARdner, J. (coords.), Relating to Responsibility. Essays for Tony Honoré on his Eightieth Birthday, Oxford-Portland, Hart, 2001. 
Cárdenas Villarreal, H. A., "La pérdida de la chance en la reciente jurisprudencia médica", en Gómez de la Torre Vargas, M. et al. (eds.), Estudios de derecho civil XIV, Santiago, Thomson Reuters, 2019.

Castronovo, C., Responsabilità civile, Milano, Giuffrè, 2018.

Cordopatri, F., s.v. "Presunzione (dir. proc. civ.)", Enciclopedia del diritto, vol. xxxv, Milano, Giuffrè, 1986.

Domínguez Águila, R., “Comentario de jurisprudencia. Reserva del derecho a discutir la especie y monto de los perjuicios", Revista de Derecho de la Universidad de Concepción, n. $^{\circ}$ 206, 1999.

Domínguez Águila, R., "Comentario de jurisprudencia. Reserva del derecho a discutir los daños. Art. 173 del código de procedimiento civil”, Revista de Derecho de la Universidad de Concepción, n. ${ }^{\circ}$ 214, 2003.

Ferrer Beltrán, J., La valoración racional de la prueba, Madrid, Marcial Pons, 2007.

Ferrer Beltrán, J., Prueba y verdad en el derecho, 2. a ed., Madrid, Marcial Pons, 2002.

Gama Leyva, R., Las presunciones en el derecho. Entre la perplejidad y la fascinación de los juristas, Valencia, Tirant lo Blanch.

Gilead, I., Green, M. y Косн, B. (eds.), Proportional Liability: Analytical and Comparative Perspectives, Tort and Insurance Law, Berlin-Boston, De Gruyter, 2013.

Gilead, I., Green, M. y Косн, B. (eds.), "General report. Causal uncertainty and proportional liability: analytical and comparative report", en GILEAD, I., GreEN, M. y Koch, B. (eds.), Proportional Liability: Analytical and Comparative Perspectives, Berlin-Boston, De Gruyter, 2013.

Green D., M., "Causal uncertainty and proportional liability in the US”, en GILEAD, I., Green, M. y Косн, B. (eds.), Proportional Liability: Analytical and Comparative Perspectives, Berlin-Boston, De Gruyter, 2013.

Green, M., "The future of proportional liability", en Stuart, M. (ed.), Exploring Tort Law, Cambridge, Cambridge University Press, 2005. 
GreEn, S., "The risk pricing principle: a pragmatic approach to causation and apportionment of damages", Law, Probability and Risk, n. ${ }^{\circ}$ 4, 2005.

HAACK, S., “Asuntos arriesgados: sobre la prueba estadística de la causación específica”, en Papayannis, D. (coord.), Causalidad y atribución de responsabilidad, Madrid, Marcial Pons, 2014.

Honoré, T., "Condiciones necesarias y suficientes en la responsabilidad extracontractual”, A. Pino y A. Ibáñez (trads.), Revista Chilena de Derecho, vol. 40, n. ${ }^{\circ}$ $3,2013$.

Hunter Ampuero, I., "Las dificultades probatorias en el proceso civil. Tratamiento doctrinal y jurisprudencial, críticas y una propuesta", Revista de Derecho, Universidad Católica del Norte, año 22, n. ${ }^{\circ} 1$.

JHERING, R. von, El elemento de la culpabilidad en el derecho privado romano, J. L. Guzmán Dalbora (trad.), Buenos Aires, Euro, 2013.

Косн, B., "Proportional liability for causal uncertainty. How to works on the basis of a 200-year-old code", en Martín-Casals, M. y Papayannis, D. (eds.), Uncertain Causation in Tort Law, Cambridge, Cambridge University Press, 2016.

Krause Muñoz, M. S., "La relación de causalidad, ¿"quaestio facti o quaestio iuris'?”, Revista de Derecho, Universidad Austral de Chile, vol. 27, n. o 2, 2014.

Lara Arroyo, J. y García-Huidobro Herrera, L., “27F: ¿terremoto en la responsabilidad del Estado?", Anuario de Doctrina y Jurisprudencia. Sentencias destacadas 2013, Santiago, Libertad y Desarrollo, 2014.

Larroucau Torres, J., "Razonamiento hermenéutico y 'hechos sustanciales controvertidos", Revista Chilena de Derecho, vol. 44, n. ${ }^{\circ}$ 1, 2017.

Larroucau Torres, J., "Sana crítica y presunción judicial”, Revista de Derecho de la Universidad de Concepción, n. ${ }^{\circ}$ 238, 2015.

Larroucau Torres, J., “CCómo se prueba la responsabilidad civil médica en la justicia chilena?", Revista de Derecho de la Universidad Austral, vol. 27, n. 2, 2014.

Larroucau Torres, J., "Hacia un estándar de prueba civil”, Revista Chilena de Derecho, vol. 39, n. $3,2012$. 
Larroucau Torres, J., “'Res ipsa loquitur': quien habla es el juez, no la cosa”, en Figueroa, G., Barros, E. y Tapia, M. (coords.), Estudios de derecho civil vi, Santiago, Legal Publishing, 2009.

Larroucau Torres, J., Culpa y dolo en la responsabilidad extracontractual, Santiago, LexisNexis, 2007.

Leshem, S. y Miller, G., “All-or-nothing versus proportionate damages”, Journal of Legal Studies, Universidad de Chicago, vol. 38, 2009.

Magnus, U., "Causal uncertainty and proportional liability in Germany”, en GILEAD, I., Green, M. y Koch, B. (eds.), Proportional Liability: Analytical and Comparative Perspectives, Berlin-Boston, De Gruyter, 2013.

Martín-Casals, M., "Proportional liability in Spain. A bridge too far?”, en MartínCasals, M. y Papayannis, D. (eds.), Uncertain Causation in Tort Law, Cambridge, Cambridge University Press, 2016.

Martín-Casals, M. y Solé, J., "Causal uncertainty and proportional liability in Spain”, en Gilead, I., Green, M. y Koch, B. (eds.), Proportional Liability: Analytical and Comparative Perspectives, Berlin-Boston, De Gruyter, 2013.

Medina Alcoz, L., La responsabilidad proporcional como solución a la incertidumbre causal, Madrid, Civitas-Thomson Reuters, 2018.

Mejías Alonzo, C., "Pérdida de una chance. Una revisión a partir de los requisitos del daño indemnizable", Gómez de la Torre Vargas, M. et al. (eds.), Estudios de derecho civil XIV, Santiago, Thomson Reuters, 2019.

Moréteau, O., "Causal uncertainty and proportional liability in France", en Gilead, I., Green, M. y Koch, B. (eds), Proportional Liability: Analytical and Comparative Perspectives, Berlin-Boston, De Gruyter, 2013.

Munita Marambio, R., "Causalidad incierta, alternativa y flexibilidad probatoria”, en Bahamondes Oyarzún, C., Etcheberry Court, L. y Pizarro Wilson, C. (eds.), Estudios de derecho civil XIII, Santiago, Thomson Reuters, 2018.

Múrtula Lafuente, V., "Causalidad alternativa e indeterminación del causante del daño en la responsabilidad civil", [en línea], InDret 2, 2006, disponible en: http://www.indret.com/pdf/351_es.pdf [consultado el 31 de enero de 2019]. 
Nocco, L., "Causalità: dalla probabilità logica (nuovamente) alla probabilità statistica, la Cassazione civile fa retromarcia", Danno e responsabilità, n. ${ }^{\circ}$ 12, 2006.

Nocco, L., "Rilevanza delle concause naturali e responsabilità proporzionale: un discutibile revirement della Cassazione”, en Danno e responsabilità, 2, 2012.

Oliphant, K., "Causal uncertainty and proportional liability in England and Wales", en Gilead, I., Green, M. y Koch, B. (eds.), Proportional Liability: Analitical and Comparative Perspectives, Berlin-Boston, De Gruyter, 2013.

Papayannis, D., Causalidad y atribución de responsabilidad, Madrid, Marcial Pons, 2014.

Papayannis, D., El derecho privado como cuestión pública, Bogotá, Universidad Externado de Colombia, 2016.

Peñailillo Arévalo, D., "Sobre el lucro cesante", Revista de Derecho Universidad de Concepción, n. ${ }^{\circ}$ 243, 2018.

Porat, A. y Stein, A., "Indeterminate causation and apportionment of damages: an essay on Holtby, Allen, and Fairchild", Oxford Journal of Legal Studies, vol. 23, n. ${ }^{\circ} 4,2003$.

Porat, A. y Stein, A., Tort Liability under Uncertainty, Oxford, Oxford University Press, 2001.

PorAt, A. y Stein, A., "Liability for uncertainty: making evidential damage actionable", Cardozo Law Review, vol. 18, 1997.

Puppe, I. y Wright, R. W. "Causation in the law: philosophy, doctrine and practice", en Infantino M. y Zervogianni, E. (eds.), Causation in European Tort Law, Cambridge, Cambridge University Press, 2017.

RatTi, G. B., "Los contrafácticos en el derecho. Un inventario de problemas", en Papayannis, D. M. (ed.), Causalidad y atribución de responsabilidad, Madrid, Marcial Pons, 2014.

Reglero Campos, F. y Bustos Lagos, J. (coords.), Tratado de responsabilidad civil, t. I, 5. ed., Cizur Menor, Thomson Reuters-Aranzadi, 2014.

Ríos, I. y SiLva, R., Responsabilidad civil por pérdida de la oportunidad, Santiago, Jurídica de Chile, 2014. 
San Martín Neira, L., La culpa de la víctima en la responsabilidad civil, Santiago, DER Ediciones, 2018.

SAn Martín Neira, L., "Responsabilidad del Estado por falta de servicio. 'Valenzuela Flores y otros con Fisco de Chile' (rol n. ${ }^{\circ}$ 1629-2013)", Roma e America, n. ${ }^{\circ} 34,2013$.

SCHIPANI, S., "Fronteras actuales del hecho ilícito y relecturas de los digestos", en Alferillo, P. et al. (coords.), Liber Amicorum en homenaje al prof. Dr. Luis Moisset de Espanés, t. I, Córdoba, Advocatus, 2010, 173-192.

SCHIPANI, S., Contributi romanistici al sistema della responsabilità extracontrattuale, Torino, Giappichelli, 2009.

Stein, A., Foundations of Evidence Law, Oxford, Oxford University Press, reimp., 2008.

STEIn, A., "The refoundation of evidence law", Canadian Journal of Law \& Jurisprudence, vol. 9, 340 .

TARuffo, M., "La prueba científica en el proceso civil", Ferrer, J. et al., Estudios sobre prueba, México, Universidad Nacional Autónoma de México, 2011.

TASSOnE, B., "Concause, orientamenti recenti e teorie sulla causalità", Danno e responsabilità, $\mathrm{n} .^{\circ} 6,2013$.

TASSONE, B., "Solidarietà e parziarietà nell'ordinamento italiano, un'analisi operazionale", Danno e responsabilità, n. ${ }^{\circ}$ 11, 2007.

VArgas Pinto, T. (ed.), "La relación de causalidad. Análisis de su relevancia en la responsabilidad civil y penal”, Cuadernos de Extensión Jurídica, n. ${ }^{\circ} 15$, Santiago, Universidad de los Andes, 2008.

WeIR, T., “All or nothing?”, Tulane Law Review, 2003-2004, 78, 2004. 